\title{
O Direito Internacional do Mar e a Conferência de Caracas*.
}

\author{
Vicente Marotta Rangel \\ Professor Titular de Direito Internacional Públlco \\ na Faculdade de Direito da Universidade \\ de São Paulo.
}

1. Faz poucas semanas se encerrou o segundo período de sessões da Terceira Conferência das Nações Unidas sobre Direito do Mar. A reunião teve lugar, como se sabe, na capital da Venezuela e, sob a presidência do Senhor Hamilton ShirLEy Amerasinghe (de Sri Lanka), perdurou de 20 de junho a 29 de agosto último. O primeiro período de sessões, de objetivo basicamente preparatório e processual, estendera-se de 3 a 15 de dezembro do ano passado, em New York, mas os resultados não foram suficientemente profícuos, o que contribuíu para agravar os encargos da reunião subseqüente.

Desdobrou-se esta em quatro etapas principais. A primeira delas, processada entre 20 e 27 de junho, abrangeu sessões plenárias destinadas à instalação solene e ao exame e aprovação do regulamento da Conferência. Transcorreu a segunda de 28 de junho a 15 de julho, compreendendo declarações gerais enunciadas por cento e quinze chefes de delegações. Representantes de diversas entidades internacionais também as formularam. Consistiu a terceira etapa nos trabalhos das Comissões principais enquanto a última, reservada para os quatro dias finais, decidiu, entre outros tópicos relevantes, sobre o local e o período da reunião subseqüente.

* Palestra proferida a 25 de setembro de 1974, a convite da Universidade de Guanajuato, por ocasiāo do " $\mathrm{X}$ Congresso do Instituto Hispano-Luso-Americano de Direito Internaclonal". 
2 Tanto quanto a Universidade, centro de ensino e de pesquisa - como o é a de Guanajuato, em que temos a honra de nos encontrar - o Instituto Hispano-Luso-Americano de Direito Internacional é o anfiteatro adequado para a exposição de temas como o que estamos a focalizar, e aos quais vem também propiciando, de forma contínua, contribuição marcante e construtiva. Qustões sobre direito internacional marítimo tem ficado inscritas na ordem do dia de pelo menos metade dos Congressos do Instituto. Foram eles examinados desde o segundo Congresso, realizado por sinal em minha Universidade, a de São Paulo, em outubro de 1953 e continuam a sê-lo no atual Congresso, o décimo de nosso Instituto. Cerca de sexta parte dos artigos publicados no último Anuário de nosso Instituto, o de número quatro, todo ele dedicado à memória do saudoso secretário-geral, Professor Luiz Garcia Arias, se refere a problemas do mar.

3. Quanto à reunião de Caracas, convém esclarecer não ter ela consistido na Terceira Conferência das Nações Unidas sobre Direito do Mar mas em sua segunda sessão. Terá lugar em Genebra, no período de 13 de março até 10 de maio do ano próximo, o terceiro período. $O$ sentido de sequêencia e de unidade da Conferência, malgrado o desdobramento dela em diversos períodos, encontra reflexo no Regulamento aprovado na recente reunião, o qual dispõe (artigo 4) que a Comissão de Credenciais terá, nos períodos subsequientes, a incumbência de examinar apenas as credenciais dos representantes que não foram anteriormente designados, salvo, segundo reza a mesma disposição, "se a Conferênica decida o contrário por maioria dos representantes presentes e votantes". O derradeiro período de sessões da Conferência, que poderá ser o quarto da série e ter lugar mesmo no ano próxi mo, mas poderá, outrossim, exigir muitas sessões precedentes e realizar-se em data remota, ocorrerá, enfim, em Caracas, como preito à cidade e ao país que tão bem agasalharam as delegações, oferecendo-lhes hospitalidade e sensibilizando-as com esmeradas atenções. $\mathrm{O}$ escopo da Terceira Conferência das 
Naçōes Unidas continua a ser, nessas condições, a conclusão da Convenção ou Convençōes de Caracas sobre Direito do Mar.

4. A referência an título de convenções como essa, no qual figuram via de regra nomes de cidades, nos impele a uma visão retrospectiva do processo de codificação das regras sobre Direito do Mar. Este processo encontra, na história das relações internacionais. três momentos culminantes: o da Conferência de Haia, de 1930, convocada sob os auspícios da Sociedade das Nacões: o das Conferências de Genebra. de 1958 e de 1960, realizadas sob os arspícios das Nacões Unidas; e, finalmente, o da Conferência de Caracas. de 1974, também realizada por convocação das Nações Unidas. A Conferência de Haia de 1930 teve competência restrita, uma vez que se propôs, de início, a codificar normas apenas sobre águas territoriais, embora, ao depois, cuidasse de outros espacos marítimos. As de Genebra tiveram, desde o começo, jurisdição material ampliada, cabendo-lhes propor a regulamentação de todos os espaços marítimos então admitidos, levando-se em consideração tanto os aspectos jurídicos como os técnicos, biológicos, econômicos e políticos pertinentes. Da Conferência das Nacões Unidas de 1958 resultaram auatro convenções: sobre mar territorial e zona contígua; sobre alto mar; sobre nesca e convenção dos recursos biológicos do mar; e sobre plataforma continental. A segunda Conferência das Nações Unidas, de 1960, prolongamento da realizada dois anos antes, foi confiado o exame de dois problemas que na nrimeira subsistiram sem solução: o da largura do mar territorial e o dos limites das zonas de pesca. Em grande parte as reuniōes de Genebra não atingiram os objetivos que inspiraram a sua convocação. A segunda reunião, de 1960 , redundou em completo malogro, enquanto a primeira, embora desse origem às quatro convenções mencionadas, não conseguiu evitar-lhes equívocos e ambigüidades, razão pela qual reduzido número de Estados se vinculou a esses acordos: apenas 49 em relação à Convenção sobre Alto Mar e sobre a Plataforma Continental; e 41 e 32 Estados, respectivamente, em relação 
às Convenções sobre Mar Territorial e sobre a Pesca e Conservação dos Recursos Biológicos do Mar. Sendo cerca de 150 os Estados membros da comunidade internacional, verifica-se que apenas um terço deles se encontram vinculados juridicamente a essas convenções.

Esta é uma das razões principais que explicam o atual processo de revisão do direito do mar. As convenções de Genebra deixaram de corresponder às necessidades e às expectativas da comunidade internacional. Com o malogro da Conferência đas Nações Unidas de 1960 , que não solucionou o problema da delimitação do mar territorial e das zonas de pesca, diversos Estados passaram a adotar medidas unilaterais visando a estabelecer essa delimitação de acordo com seus interesses individuais ou regionais. A convenção sobre plataforma continental não estabeleceu, por outro lado, com precisão, o limite exterior dessa plataforma, o oual poderá ser distendido até onde a capacidade tecnológica de cada Estado o permita.

$\mathrm{O}$ receio de que os fundos oceânicos, sobretudo os situados nas adjacências da plataforma continental, se submetessem cada vez mais às soberanias nacionais e se convertessem em centro de competições acirradas, foi a principal razão da proposta apresentada no mes de setembro de 1967, perante a Assembléia Geral das Nações Unidas pelo Embaixador Arvid Pardo, delegado de Malta. Aprovada a inclusão de novo tema na agenda da xxIıa sessão da Assembléia Geral, que então se iniciava, foi a seguir criado um Comité Especial, composto por 35 Estados, para estudar a utilização, com fins pacíficos, dos fundos marítimos e oceânicos situados fora dos limites de jurisdição nacional (resolução 2340-xxı) A 21 de dezembro de 1968, a Assembléia Geral aprovou as resoluções 2467 A, B, C e D (xxIII), pelas quais se estabeleceu a Comissão sobre a Utilização com Fins Pacíficos dos Fundos Marítimos e Oceânicos situados fora dos limites da Jurisdição Nacional. Integrada, inicialmente por 42 Estados Membros, foi a Comissão ampliada, sucessivamente, com mais 44 e com mais 5 
membros, de sorte a abranger finalmente 91 Estados. Ficou essa Comissão incumbida pelas resoluções 2750 A, B e c (xxv), Comissão incumbida pelas resoluções 2750 A, B e C (XXV), de 17 de dezembro de 1970, de promover os trabalhos preparatórios de nova conferência sobre Direito do Mar, cuja convocação as mesemas resoluções haviam previsto para 1973. Com esse objetivo, a Comissão, após uma série de reuniões em New York e em Genebra, apresentou nesse mesmo ano à Assembléia Geral um relatório sobre suas deliberações, inclusive a documentação respectiva, material esse finalmente remetido a exame da Terceira Conferência das Nações Unidas sobre Direito do Mar, a qual acabou se realizando em data posterior à inicialmente prevista.

5. E oportuno cotejar a composição dessa Conferência com as que a precederam.

Representaram-se na Conferência de Haia quarenta e oito Estados, tendo freqüentado a Segunda Comissão (sobre "Mar Territorial") reduzido contingente de Estados latinoamericanos: México, Brasil, Chile, Colombia, Cuba, Uruguai.

Da Conferência das Nações Unidas de 1958 participaram oitenta e seis Estados, ou seja, quase o dobro dos que estiveram presentes em Haia, além de observadores de agências especializadas das Nações Unidas e de diversas organizações intergovernamentais. Havia vinte e dois países asiáticos, vinte latino-americanos e seis africanos. À Conferência de 1960 compareceram representantes de oitenta e dois Estados, a saber, dois a mais que na anterior.

Realizada quase três lustros após, a reunião de Caracas foi a que, até hoje, maior número de Estados abrangeu. Pela complexidade dos assuntos, duração longa e ampla composiçāo, tem sido ela considerada uma das mais importantes de todas quantas até hoje celebradas. Dos 149 Estados convidados, dos quais 14 não eram membros das Nações Unidas, 138 acabaram da reunião participando. Além de três mil delegados, estiveram presentes cerca de dois mil observadores. Entre os Esta- 
dos participantes, figuraram em sensível maioria, os pertencentes ao Terceiro Mundo. Quarenta e dois, ou seja, mais de um quarto, eram membros da Organização da Unidade Africana. Da América Latina compareceram 24 Estados, menos de um quinto dos participantes.

Para se ter idéia mais nítida da composição assim como da competência da reunião, convém anotar o comparecimento, como observadores, das seguintes entidades internacionais: Organização Hidrográfica Internacional; Organização da Unidade Africana; Liga dos Estados Árabes; Comissão Permarıente do Pacífico Sul; Organização dos Estados Americanos; Organização Consultiva Marítima Intergovernamental; Organização das Nações Unidas para a Educação, Ciência e Cultura; Organização das Nações Unidas para a Agricultura e Alimentação; Agência Internacional de Energia Atômica; Programa das Nações Unidas sobre o Meio Ambiente e Conferência das Nações Unidas sobre Comércio e Desenvolvimento. Compareceu também o Conselho das Nações Unidas para Namíbia.

No decurso da reunião, decidiu-se convidar a dela participarem como observadores doze "movimentos de libertação nacional" reconhecidos pela Organização da Unidade Africana e pela Liga dos Estados Árabes, a saber: Movimento Popular de Libertação de Angola (MPLA) e Frente Nacional da Libertação de Angola (FMLA), por Angola; Frente de Libertação do Povo da África Sul Ocidental (ZWAMPo), por Namíbia; União Nacional Africana de Zimbabuwe (ZANU) e União do Povo Africano de Zimbabuwe (ZAPU), por Rodésia-Zimbabuwe; Congresso Nacional Africano de Sul-África (ANC) por África do Sul; Movimento de Libertação Nacional dos Comores (MOLINACO), pelas Ilhas Comores; Partido Unificado do Povo (SPup) e Partido Democrático, pelas Ilhas Seychelles (SPUP) ; Frente Nacional de Libertação das Costas da Somália (FLCF), pela Costa da Somália; e Organização da Libertação da Palestina (OLP), pela Palestina. 
Deliberou-se, outrossim, recomendar à Assembléia Geral das Nações Unidas que tomassem assento na Conferência, na qualidade de observadores, algumas coletividades em vias de emancipação política. Alcançada essa emancipação, passarão a ser membros de pleno direito da Conferência. Tratase da Papua Nova Guinea, das Ilhas Cook assim como de Surinam e das Antilhas Holandesas. Estas duas últimas comunidades tiveram, aliás, sua próxima independência anunciada em plenário pelo chefe da delegação dos Países Baixos.

6. Ficou aprovado, após intensos debates, a 27 de junho de 1974, o Regulamento da Terceira Conferência das Nações Unidas sobre Direito do Mar. A 12 de julho do mesmo ano, foi, pela primeira vez, emendado. Dispõe o Regulamento que o Secretário Geral das Nações Unidas, ou seu representante especial, atua como tal em todas as reuniōes da Conferência, suas Comissões e seus órgãos subsidiários. Distinguem-se as decisões sobre assuntos de fundo daquelas sobre processo. As primeiras, inclusive a adoção do texto da Convenção sobre Direito do Mar em seu conjunto, se tomam por maioria de dois terços dos representantes presentes e votantes, sempre que essa maioria compreenda pelo menos maioria dos Estados participantes do mesmo período de sessões. As segundas se tomam por maioria dos representantes presentes e votantes.

Releva notar que nenhum assunto de fundo será votado sem que a maioria de dois terços da Conferência determine previamente que tenham sido exauridos todos os esforços para chegar a um acordo geral. É mister também que o anúncio da votação se publique no Diário da Conferência e que dois dias úteis transcorram após a publicação.

Declaração feita pelo Presidente da Conferência e aprovada por esta a 27 de junho de 1974 incorporou ao Regulamento o "Acordo de Cavalheiros" aprovado pela Assembléia Geral das Nações Unidas a 16 de novembro de 1973. 
Diz esse Acordo o seguinte: "Tendo presente que os problemas do espaço oceânico estão estreitamente relacionados entre si e devem considerar-se como um todo, e a conveniência de adotar uma Convenção sobre o Direito do Mar que logre a maior aceitação possível, a Conferência deve fazer todos os esforços para que os acordos sobre os assuntos se tomem por consenso, e referidos assuntos não devem ser subinetidos à votação enquanto não se ajam esgotado todos os esforços para se chegar a um consenso"

Esta ênfase dada ao consenso como processo prioritário de tomada de decisões mostra uma das razões pelas quais a reunião de Caracas não pode levar a cabo a conclusão de tratado internacional, como era expectativa reinante. $\mathrm{O}$ processo do consenso pressupõe a conscientização, por parte das delegações, de que as normas sobre direito do mar devam ser aceitas pelos Estados em sua unanimidade ou quase totalidade. E dessa forma que essas normas se imporão como expressão indeclinável das aspirações da comunidade internacional. Para essa conscientização, mister se faz, porém, o transcurso de um determinado período, a aquisição de um certo grau de maturidade que a reunião de Caracas esteve longe de atingir.

$E$ interessante notar que o consenso introduz novo elemento na processualística da conclusão dos tratados internacionais e sobre ele a prática revela uma certa hesitação. "Que es lo que significa el consenso?", indaga Constantin A. StavRopoulos, subsecretário das Nações Unidas. Depois de declarar que poderá ser precipitado tratar de condensar alguma prática sobre o consenso nas Nações Unidas, observa parecer ele significar que u'a minoria de delegações discrepantes do texto a ser votado está disposta "simplesmente a manifestar sus reservas para que sean registradas, en lugar de insistir en una votación en contra" "No necesita obligatoriamente" acrescenta o mesmo jurista, - "una regla de unanimidad que requiere del poder afirmativo de la totalidad de los participan- 
tes, lo que los darían un poder de veto a cada uno de ellos. En esencia, es una manera de proceder sin objeciones formales". Nesse particular, há uma influência do processo de conclusão dos órgãos internacionais, onde a prática subsiste há bastante tempo. Quando se afirma, por exemplo, que a Declaração Universal das Nações Unidas sobre Direitos Humanos foi aprovada sem votos contrários, não é mister fazer menção às abstenções que então ocorreram. Para se conferir maior grau de eficácia às recomendações, importa sejam aprovadas sem votos contrários, vale dizer, mediante consenso. Embora os tratados internacionais segundo o processo clássico de conclusão, necessitem de serem ratificados, exigência a ser feita na futura convenção sobre direito do mar, o fato é que a aprovação deles, em conferência internacional, por via de consenso, lhes conferirá "ab initio" prestígio e autoridade.

7 Outras razões, igualmente imperiosas, explicam o relativo malogro da reunião de Caracas.

Enquanto a Conferência de Haia de 1930 se concentrava no exame das bases de discussão redigidas por uma Comissão preparatória composta de cinco membros, bases essas endereçadas aos governos interessados dez meses antes que aquela fosse instalada, a Conferência de 1958 teve como foco de sua análise projeto de setenta e três artigos e respectivos comentários, elaborados pela Comissão de Direito Internacional das Nações Unidas durante o período de 1950 a 1956. A reunião de Caracas não contou, porém, senão com documentos enfeixados em seis volumes produzidos pela Comissão dos Fundos Oceânicos, nos quais se mesclam projetos preliminares, usualmente em forma de alternativas ou hipóteses, e propostas de diversos Estados. Tratava-se de matéria apresentada ainda sob roupagem complexa, rude, intrincada. Coube, de conseguinte, à própria reunião de Caracas iniciar uma tarefa preliminar e necessária, do qual haviam sido dispensadas as Conferências precedentes. Para a realização desse encargo foi a reunião obrigada a consumir quase todo o tempo de que dispunha. O tempo restante, cerca de duas semanas, ficou destinado à 
aprovação do regulamento e às declarações gerais das delegações em plenário.

O grande número de Estados participantes, quase o dobro das Conferências de Genebra e cerca do quádruplo da de Haia, indica, por outro, as dificuldades maiores da reunião. Acresce notar a complexidade e variedade do temário. Alguns de seus tópicos não constavam das agendas das reuniões anteriores, pelos menos com caráter específico, tais como os relativos ao regime dos fundos oceânicos e o de pesquisa e transferência tecnológica.

8. São três as principais comissões da Conferência, cada qual realizando uma tarefa específica.

A primeira Comissão tem por objetivo principal elaborar projetos de artigos de tratado sobre o regime internacional dos fundos marítimos situados além da jurísdição nacional. Os limites dessa jurisdição constituem objeto de discussão da segunda Comissão que, entre outros ítens do temário, cuida do regime da plataforma continental. Como se disse acima, foi a imprecisão dos limites dessa plataforma uma das razões marcantes da crise atual do direito do mar. Ao examinar esse objetivo, a Primeira Comissão se propõe a estudar o mecanismo internacional a ser instiutído para fins de regulamentar e supervisionar o regime jurídico dos fundos oceânicos. Ela se tem orientado principalmente pela resolução 2749 (xxv) da Assembléia Geral das Nações Unidas em que se declararam os princípios aplicáveis às zonas dos fundos oceânicos. Estes são considerados "patrimônio" comum da humanidade"

Problema crucial que se teve de enfrentar, como lembrou o presidente da Comissão, Sr. Paul B. Engo (dos Camarões), no encerramento dos trabalhos, consistiu em saber a quem compete explorar e explotar a área do fundo oceânico. "A máxima opção que nesse sentido se deve fazer é entre a explotação por parte da autoridade internacional ou o monopólio 
de facto por parte de uns poucos países desenvolvidos tecnologicamente, através de um sistema de licenças" Em termos de Comissão, disse ainda o presidente, "não há muito que mostrar como resultado das negociaçōes", mas se espera voltar à próxima sessão "com ânimo de negociar", para a qual, aliás, o Secretário do órgão prepararia estudo adicional sobre as implicações econômicas da mineração dos fundos oceânicos no qual ese tomariam em conta as discussões anteriores.

Evidencia-se o interesse crescente sobre as controvérsias em torno do regime dos fundos oceânicos pelo fato de neles se localizarem riquezas consideráveis, ainda nem de longe por ora determinadas. A exploração dessas riquezas, à margem de qualquer regulamentação internacional, pode acarretar, por outro lado, profundo desequilíbrio na economia de países, sobretudo dos menos desenvolvidos. E tranqüilizador, porém, saber, que em relação aos nódulos de manganês, se calcula que eles se formam nas condições presentes, num rítmo de quase dez milhões de toneladas por ano, isto é, num rítmo mais acelerado que a capacidade de exploração atualmente prevista. Interesse imediato reside, em verdade, na produção de gás e de petróleo que atinge cerca de $90 \%$ do valor da produção total dos recursos minerais do mar. A extração do petróleo submarino sextuplicou desde 1960. Avaliam-se as reservas atuais desse petróleo em cerca de $21 \%$ da reserva mundial total e se estima que para 1980 ele representará $35 \%$ aproximadamente da produção mundial.

9. Ao contrário da Primeira Comissão, envolta principalmente no exame e discussão de temas sobremodo recentes, a Segunda cuidou de questões versadas nas precedentes Conferências: zona contígüa, mar territorial, estreitos usados para a navegação internacional, plataforma continental, direitos preferenciais dos Estados costeiros, alto mar, ilhas, arquipélagos. Ao passo que tais temas demandaram novo reexame e reaprofundamento, outros surgiram no âmbito da Comissão com certo caráter de novidades, consequiências do influxo de 
fatores tecnológicos, políticos e econômicos ou de necessidade de reformulação jurídica. Do temário da Comissão constavam, desse modo, ítens como "zona econômica exclusiva" e transmissões a partir do alto mar"

A Comissão não chegou a tomar nenhuma decisão sobre questões de fundo ou sobre qualquer artigo da futura Convenção. Ela logrou preparar uma série de treze documentos de trabalho, os quais refletem as principais tendências manifestadas nas propostas então apresentadas. Esses documentos, que concernem a cada ítem da agenda da Comissão, foram submetidos, quer em versão original, quer em primeira revisão, quer ainda, em muitos casos, em segunda revisão, ao exame das delegações e da própria Comissão. Reagrupados finalmente em razão de afinidades entre eles existentes, esses documentos visaram a prociciar estímulo à negociação assim como redução das alternativas deles constantes. Tal propósito deverá ser alcançado na próxima sessão da Conferência. Segundo entendimento pessoal do Presidente da Comissão, Embaixador Andrés Aguilar (da Venezuela), as posições nela dominantes giraram, pelo menos enquanto a sessã̃o prosseguia, "em torno da tese de um mar territorial de doze milhas e de uma zona econômica exclusiva, além desse inar, até uma distância máxima que complete as duzentas miThas" A aceitação dessa tese está condicionada, porém, segundo o mesmo presidente, à solução satisfatória de outras questões, principalmente a de passagem pelos estreitos utilizados para a navegação internacional, o limite exterior da plataforma continental e a própria subsistência dessa noção e, "por último, às aspirações dos países sem litoral e de outros países que, por esta ou aquela razão, se consideram em situação geográfica desvantajosa"

10. Presidida pelo Embaixador AleXander Yankov (da Bulgária), coube à Terceira Comissão, finalmente, estudar projetos de artigos referentes à preservação do meio marítimo, à pesquisa científica do mar assim como ao desenvolvimento 
e transferência de tecnologia. Quanto à preservação do meio marinho, constava do temário ítens referentes às fontes de poluição e medidas para combatê-las; recursos para a preservação do equilíbrio ecológico do meio marinho; direitos, deveres, responsabilidade dos Estados, cooperação internacional. Para o exame desses ítens, realizaram-se sessōes informais sob a presidência do Sr. J. L. Vallarta (do México) Quanto à pesquisa científica do mar e ao desenvolvimento e transferência de tecnologia, impôs-se o exame de ítens como natureza, característicos e objetivos dessa pesquisa, acesso à informação científica, distribuição equitativa do conhecimento e da tecnologia entre países desenvolvidos e em desenvolvimento e transferência de tecnologia, a esses últimos países. Sessões informais foram, para tanto, presididas pelo Sr. CoRONEL METTERNich (da República Federal da Alemanha). Ambos os grupos de sessões informais, conduzidas pelos mesmos dois presidentes, deram origem a "grupos de redação e negociaçãa", os quais, contudo, não chegaram a produzir textos definitivos. Enquanto o primeiro grupo propendeu para reafirmar os princípios da Conferência sobre o Meio Ambiente de Estocolmo, o segundo elaborou um conjunto de princípios gerais sobre o fomento de investigação científica e artigos consolidados relativos à cooperação internacional e regional. No dizer do presidente da Comissão, houve, em geral, "espírito de transação", o qual se espera prevaleça "nos trabalhos futuros visando à superação dos problemas pendentes".

11. Em seu término, a sessão de Caracas acabou produzindo os seguintes documentos: 1) declaração concisa de caráter informativo, referente ao trabalho de cada uma das Comissões principais; 2) as declaraçōes verbais dos Presidentes dessas Comissões, em que se resume o progresso dos trabalhos realizados; 3) exposição do relator geral sobre o trabalho do plenário; 4) declaração verbal final do Presidente sumariando os resultados dos trabalhos da sessão; 5) carta dirigida pelo Presidente da Conferência ao Presidente da Assembléia Geral. sobre convite aos "movimentos de liberação nacional". 
12. Da reunião de Caracas se pode afirmar, em síntese, que ela teve por escopo não apenas sanar as lacunas das quatro convenções de Genebra sobre direito do mar mas teve também o propósito de revê-las. Ela colimou, outrossim, regulamentar novas matérias, de solver questões jamais consideradas em reuniões anteriores, questões essas que passaram por si sós a significar uma profunda revisão da problemática do direito cluássico do mar. Tratava-se aí não apenas de problemas novos mas também, com a mera postulação desses problemas, de uma filosofia diferente sobre os valores, sobre os fatos e sobre as normas que compõem o novo direito do mar. Tratava-se, como se trata, de uma nova regulamentação em que se fazem sentir os interesses, até agora insuficientemente protegidos, dos países em desenvolvimento, postos à margem dos benefícios da utilização e da conservação dos recursos do mar a dos fundos oceânicos em virtude de um direito tradicional assentado em fontes precipuamente consuetudinárias. Os costumes internacionais que as convenções de Genebra buscavam codificar, inclusive os de formação então recente como os originados da prática da doutrina Truman sobre a plataforma continental, resultaram, em grande parte, de atos elaborados por Estados tradicionalmente empenhados na exploração dos espaços oceânicos. Tais atos que não encontravam, em regra, oposição formal dos demais países, em geral mais clébeis, e até mesmo incapacitados para a utilização desses espaços, adquiriram o beneplácito a apoio da doutrina, via da regra concebida e ensinadas nos mesmos países habilitados para essa utilização.

Com assento em costumes internacionais, por eles próprios gerados, acolhidos e protegidos e com o favor da doutrina em seu âmbito elaborada e difundida, os países efetivamenie desenvolvidos, militarmente fortes, providos de uma armada poderosa, foram progressiva e decididamente, desde a Idade Moderna, estruturando normas e valores que compuseram - direito internacional clássico que encontra nas convenções de Genebra a sua forma mais aperfeiçoada de cristalização. 
O desejo de modificá-las esteve patente na palavra e no espírito dos debates da reunião de Caracas. Como assinalou, por exemplo, o Presidente da Terceira Comissão, dois fatores no mundo contemporâneo - mudanças políticas e sociais e o desafio da resolução tecnológica - clamam por um reajustamento da ordem jurídica dos oceanos para que se adapte às novas realidades. $\mathrm{O}$ uso pacífico do mar adquiriu novas dimensões. A riqueza natural do mar oferece agora novas oportunidades em áreas críticas da economia mundial como a crescente demanda da energia e de matérias primas, inclusive minerais e proteinas. Por outro lado, a proteção do meio marítimo tornou-se, ao mesmo tempo, uma parte essencial da proteção do meio ambiente global"

Enquanto as convenções de Genebra constituem, em grande parte, diplomas de alcance restrito quanto ao âmbito de validade espacial e quanto ao âmbito de validade material, as normas consuetudinárias a respeito abrangem o "uso constante e uniforme, aceito como direito", requisito mencionado pela Corte Internacional de Justiça no caso do Direito de Asilo. A prática dos Estados também não se mostra "extensiva e virtualmente uniforme", requisitos a que a mesma Corte aludia no caso da "Plataforma Continental do Mar do Nortu" Sobre os requisitos do costume tornou a Corte a referirse nos pleitos sobre "Jurisdição de Pesca" em que contra a Islandia demandas foram intentadas pelo Reino Unido da Grã Bretanha e pela República Federal da Alemanha. Em sentença de 25 de julho último, proletada aliás enquanto estava em curso a reunião de Caracas, a Corte Internacional de Justiça decidiu, for maioria de votos (dez contra quatro) que os regulamentos promulgados pelo governo da Islandia a 4 de julho de 1952, autorizando a ampliação dos direitos exclusivos de pesca deste país, até cincoenta milhas, não poderiam prevalecer sobre os direitos históricos dos Estados autores. A Corte não declarou, porém, como o requereram estes Estados, que tal ampliação não tinha fundamento no direito internacional e era inválida erga omnes. Como esclareceram os juizes 
Forster, Bergzon, Jimenez de Aréchaga, Nagendra Singh e RudA, que sufragaram a sentença da Corte, não se poderia afirmar haver costume internacional proibindo a majoração da jurisdição de pesca exclusiva além de 12 milhas marítimas contadas das linhas bases: "existe no presente uma situação de incerteza quanto à existência de regra costumeira prescrevendo um limite máximo da jurisdição de pesca de um Estado" Fisheries Juristiction (United Kingdon v. Iceland, Merits, Judgement. I.C.J. Reports 1974, p. 52.)

Esta situação de incerteza persiste, igualmente, em outros domínios do direito do mar, mesmo porque também neles há carência de normas, há problemas novos, há inclusive áreas do globo terrestre como os fundos oceânicos aguardando uma primeira regulamentação.

"Inegavelmente, esta situação de incerteza jurídica" ponderam, com razão, esses juízes - "é insatisfatória e propiciadora de ficção e disputas internacionais. Espera-se, contudo, que o direito a respeito possa ser qualificado como o resultado de esforços destinados à sua codificação e desenvolvimento progressivo, os quais estão ora sendo feitos na Conferência de Caracas"

Não tendo essa reunião, contudo, levado a termo essa tarefa, o momento é oportuno para reafirmar a necessidade de intensificar esforços em prol da harmonização do direito do mar com as realidades e fatores que lhe são subjacentes. Mais que isso, todavia. Importa que, em bases de justiça e de equidade, venha esse direito a ser alavanca propulsora do desenvolvimento dos países necessitados e da redefinição das estruturas de um mundo em transformação. $\mathrm{O}$ esforço ordenado dos países de nossa comunidade pode contribuir, decisivamente, para a formulação do novo direito e para o satisfatório atendimento das aspirações e expectativas dominantes em nossos povos, as quais se encontram, como vimos, nas origens da convocação da Terceira Conferência das Naçōes Unidas sobre Direito do Mar. 